\title{
Serum Homocysteine Level in Type 2 Diabetes Mellitus with Peripheral Arterial Disease
}

\author{
H Howlader ${ }^{1}$, S Ahmed ${ }^{2}$, N Sultana ${ }^{3}$, Z Hasan ${ }^{4}$, U Sadia ${ }^{5}$, S Ferdousi ${ }^{3}$ \\ ${ }^{1}$ Dept of Biochemistry, Sher-E-Bangla Medical College, Barisal \\ ${ }^{2}$ Dept of Biochemistry, Popular Medical College, Dhaka \\ ${ }^{3}$ Dept of Biochemistry, Dhaka Medical College, Dhaka \\ ${ }^{4}$ Dept of Physiology, BIRDEM Academy, Dhaka \\ ${ }^{5}$ Bangladesh Institute of Health Sciences (BIHS) and Hospital, Dhaka \\ ${ }^{6}$ Dept of Biochemistry, Dhaka Medical College, Dhaka
}

\section{ABSTRACT}

Peripheral arterial disease is a macrovascular complication of type 2 diabetes mellitus. Hyper-homocysteinemia is found to be associated with peripheral arterial disease. Homocysteine induced endothelial-cell injury is mediated by hydrogen peroxide. Hydrogen peroxide exposes the underlying matrix and smooth muscle cells of the arteries which, in turn, proliferate and promote the activation of platelets and leukocytes. The present study was carried out in the Department of Biochemistry, Dhaka Medical College, Dhaka from July 2010 to June 2011 to observe the association of hyperhomocysteinemia with peripheral arterial disease in type 2 diabetes mellitus. A total of 100 subjects (50 cases and 50 controls) were selected by purposive sampling from Bangladesh Institute of Health sciences (BIHS) and BIRDEM Hospital, Dhaka. Subjects having ankle brachial index $<0.9$ were considered as cases and those having ankle brachial index $\geq 0.9$ were considered as controls. Subjects with absent peripheral pulses or nonrecordable ankle brachial index were considered as ankle brachial index $<0.9$. All study subjects were normotensive, normolipidemic and non- smoker. The study showed a higher level of homocysteine $(\mu \mathrm{mol} / \mathrm{L})$ in cases when compared with that of controls $(15.95 \pm 1.80$ vs. $9.31 \pm 2.11 ; \mathrm{p}<0.001)$. In cases, males had higher proportion of arterial disease $(56 \%)$ than females. Other variables (age and body mass index) showed no significant difference between two groups.

Key Words: Diabetes Mellitus, Ankle Brachial Index, Peripheral Arterial Disease, Homocysteine

\section{Introduction}

Diabetes mellitus (DM) is a clinical syndrome characterized by hyperglycemia caused by absolute or relative deficiency of insulin. Type 2 diabetes mellitus is a more complex condition than type 1 diabetes because there is a combination of resistance to the actions of insulin in liver and muscle together with impaired pancreatic $\beta$ cell function leading to relative insulin deficiency. Incidence of both type 1 and type $2 \mathrm{DM}$ are increasing. It is estimated that, in the year 2000, 171 million peoples had diabetes and this is expected to double by 2030 . The prevalence of known diabetes in urban areas of Indian subcontinent is $>12 \%$. Patients with long standing diabetes are at risk of developing both microvascular and macrovascular complications. Microvascular complications are nephropathy, neuropathy and retinopathy and that of macrovascular are myocardial infarction, stroke and peripheral arterial disease ${ }^{1}$. 
Peripheral arterial disease (PAD) is a manifestation of systemic atherosclerosis in which arterial lumen of lower extremities becomes progressively occluded by atherosclerotic plaque ${ }^{2}$. A cross-sectional study with 97,034 study subjects, found $8.7 \%$ prevalence of PAD among patients with type 1 and a $23.5 \%$ prevalence of PAD among patients with type 2 diabetes mellitus in English community ${ }^{3}$. Another case-control study reported $18.7 \%$ prevalence of PAD in Romanian population4. Prevalence of PAD in long-term NIDDM of South Indian over 25 years duration was $15.4 \% 5$.

Atherosclerotic risk factors are traditional and non-traditional. The traditional risk factors are hypercholesterolemia, hypertension, type $2 \mathrm{DM}$ and smoking6. Non-traditional risk factors for atherosclerosis are insulin resistance, endothelial dysfunction, fibrinolysis abnormalities, inflammation, microalbuminuria, hyperhomocysteinemia, postprandial glucose abnormalities and vascular wall abnormalities ${ }^{7}$.

Multiple prospective and case-control studies found that moderately elevated plasma homocysteine (Hcy) concentration is an independent risk factor for atherothrombotic vascular disease. Homocysteine concentration was found to be higher in patients with peripheral vascular, cerebrovascular and coronary artery diseases than those without such diseases ${ }^{8}$. Hyperhomocysteinemia is now considered as an independent risk factor for vascular diseases ${ }^{9}$.

Epidemiologic studies have showed that plasma Hcy levels are inversely related to plasma level of vitamin $\mathrm{B}_{6}$, folate and vitamin $\mathrm{B}_{12}$ - the three vitamins involved in the conversion of Hcy to methionine or cysteine. Supplementation of these three vitamins has been shown to reduce circulating levels of Hcy. Large elevation of plasma homocysteine occurs as a result of deficiencies in cystathionine $\beta$ synthase seen in patients with classic homocystinuria. These individuals experience premature vascular disease and about $25 \%$ of whom sustain premature death from thrombotic complications before 30 years of age $\mathrm{e}^{10}$.
PAD is one of the macrovascular complications of DM and leads to grave complication like gangrene in the lower limbs. Till today, no data are available regarding association between hyperhomocysteinemia and PAD among type 2 diabetic patients in Bangladeshi population.

Therefore, the aim of the study was to evaluate the association between hyperhomocysteinemia and peripheral arterial disease in type 2 diabetes that might be helpful for the prevention and management of peripheral arterial disease in Bangladesh.

\section{Materials and Methods}

This case-control study was conducted in the Department of Biochemistry, Dhaka Medical College, Dhaka during the period from July 2010 to June 2011. A total of 100 study subjects, both males and females, with age range of 40 to 50 years, 50 of which were type 2 diabetic patients with peripheral arterial disease $(\mathrm{ABI}<0.9)$ were cases and another 50 type 2 diabetic patients without peripheral arterial disease $(A B I \geq 0.9)$ were considered as controls. Peripheral Arterial Disease was diagnosed if ankle brachial index (ABI) $-<0.9$. Subjects with absent peripheral pulses or nonrecordable ankle brachial index was considered as ankle brachial index $(\mathrm{ABI})<0.9^{11}$.

The subjects were selected purposively from Bangladesh Institute of Health Sciences (BIHS) and BIRDEM Hospital, Dhaka. Diabetes was diagnosed if fasting blood glucose level is $\geq 7.0$ $\mathrm{mmol} / \mathrm{L}$ or blood glucose level 2 hours after 75 $\mathrm{gm}$ oral glucose intake is $\geq 11.1 \mathrm{mmol} / \mathrm{L}$. Peripheral arterial disease was diagnosed if ankle brachial index $(A B I)$ is $<0.9$. All study subjects were normotensive and nomolipidemic. Systolic blood pressure of $120-140 \mathrm{mmHg}$ and diastolic blood pressure of $60-90 \mathrm{mmHg}$ were considered as normal. Hyperhomocysteinemia was defined as serum homocysteine level $>15$ $\mu \mathrm{mol} / \mathrm{L}$. Serum tota lcholesterol level $<200$ $\mathrm{mg} / \mathrm{dl}$, serum triacylglycerol level $<150 \mathrm{mg} / \mathrm{dl}$, serum HDL-C $>40 \mathrm{mg} / \mathrm{dl}$ in male and $>50$ $\mathrm{mg} / \mathrm{dl}$ in females and LDL-C $<100 \mathrm{mg} / \mathrm{dl}$ were considered as normal. 
Subjects with history of smoking, acute infection, hepatic failure, renal failure, malignancy and connective tissue disorders were excluded from the study. Subjects receiving methotrexate, carbamazepine, phenytoin, metformin, fibric acid derivatives and vitamin B complexes were also excluded from the study.

Anthropometric measurement was taken as follows: Standing height of study subjects were measured using appropriate scales (detect-medic, Detecto scales Inc, USA) with minimal cloths without shoes to the nearest $5 \mathrm{~mm}$ if the reading fell down two values. Weight was measured by a standard weight-measuring device placed on a hard flat surface and checked for zero (0) balance before measurement. The subjects were in the centre of the platform wearing light cloths without shoes and weight was recorded to the nearest $0.5 \mathrm{~kg}$. Body mass index (BMI) of the subjects was calculated using standard formula: $\mathrm{BMI}=$ Weight $(\mathrm{Kg}) /$ Height $\left(\mathrm{m}^{2}\right)$. Serum total homocysteine was estimated by Fluorescence Polarization Immunoassay (FPIA) in AxSYM system.

Statistical analysis was done by using SPSS version 15 for windows. Mean values of the findings were compared between two groups. Categorical variables were analyzed by using unpaired students' $\mathrm{t}$ test, $\mathrm{x}^{2}$ test and Fisher's exact test. For all the statistical analysis, 2- tailed $p$ value $<0.05$ was considered as level of significance.

\section{Results}

Mean $( \pm \mathrm{SD})$ of ages in cases and controls were $62.16 \pm 6.72$ and $61.90 \pm 7.14$ years respectively. In cases $56 \%$ study subjects were males and $44 \%$ were females. In controls, ratio of male to female was $1: 1$. Proportion of male was higher than female in cases. Mean $( \pm S D)$ of BMI in cases and controls were 23.09 \pm 3.57 $\mathrm{kg} / \mathrm{m}^{2}$ and $22.45 \pm 3.11 \mathrm{~kg} / \mathrm{m}^{2}$ respectively. In both cases and controls, BMI were normal $\left(18.5-25.9 \mathrm{~kg} / \mathrm{m}^{2}\right)$ in maximum number of subjects, $60 \%$ and $70 \%$ respectively, followed by overweight $\left(25.0-29.9 \mathrm{~kg} / \mathrm{m}^{2}\right)$ in $32 \%$ and $26 \%$ subjects respectively, and below normal $\left(<18.5 \mathrm{~kg} / \mathrm{m}^{2}\right)$ in $8 \%$ and $4 \%$ subjects respectively. Mean $( \pm$ SD) of systolic blood pressure in cases and controls were $133.10 \pm 8.14$ $\mathrm{mmHg}$ and $133.60 \pm 8.87 \mathrm{mmHg}$ respectively. Mean $( \pm \mathrm{SD})$ of diastolic blood pressure in cases and controls were $84.60 \pm 5.52 \mathrm{mmHg}$ and $84.60 \pm 6.84 \mathrm{mmHg}$ respectively. Mean $( \pm \mathrm{SD})$ of serum total homocysteine in cases was $15.95 \pm 1.80 \mu \mathrm{mol} / \mathrm{L}$ and that in controls was $9.31 \pm 2.11 \mu \mathrm{mol} / \mathrm{L}$. Mean $( \pm \mathrm{SD})$ of serum total homocysteine level in cases was significantly higher than that of controls $(\mathrm{p}<0.001)$. Serum total Hcy level $\leq 15 \mu \mathrm{mol} / \mathrm{L}$ was found in $17(34 \%)$ and level $>15 \mu \mathrm{mol} / \mathrm{L}$ was found in $33(66 \%)$ of cases. Serum total homocysteine level was $\leq 15$ $\mu \mathrm{mol} / \mathrm{L}$ in all $(100 \%)$ of the controls. The distribution showed significant difference between cases and controls $(p<0.001)$.

Table I: Characteristics of study subjects

\begin{tabular}{lcccc}
\hline Variables & Cases & controls & t value & P value \\
\hline Age (years) & $62.16 \pm 6.72$ & $61.90 \pm 7.14$ & 0.188 & $0.852 \mathrm{~ns}$ \\
BMI $\left(\mathrm{kg} / \mathrm{m}^{2}\right)$ & $23.09 \pm 3.57$ & $22.45 \pm 3.11$ & 0.957 & $0.341 \mathrm{~ns}$ \\
$\begin{array}{l}\text { Serum Hcy } \\
(\mu \mathrm{mol} / \mathrm{L})\end{array}$ & $15.95 \pm 1.80$ & $9.31 \pm 2.11$ & 16.930 & $0.0001 * * *$ \\
\hline
\end{tabular}

$n s_{\text {not significant, }} \quad * * *$ Highly significant

Table-II: Distribution of the study subjects according to gender ns not significant

\begin{tabular}{llllll}
\hline Gender & \multicolumn{2}{l}{ Cases $(\mathbf{n}=\mathbf{5 0 )}$} & \multicolumn{2}{c}{ Controls $\left(\mathbf{n}=\mathbf{5 0 )} \mathbf{x}^{\mathbf{2}}\right.$ value } & $\mathbf{p}$ value \\
\hline Male & $28(56 \%)$ & 25 & $(50 \%)$ & 0.362 & $>0.05 \mathrm{~ns}$ \\
Female & $22(44 \%)$ & 25 & $(50)$ & &
\end{tabular}

$n s$ not significant

Table-III: Distribution of the study subjects according to serum total homocysteine level

\begin{tabular}{lcllll}
\hline $\begin{array}{c}\text { Homocysteine } \\
(\mu \mathbf{m o l} / \mathbf{L})\end{array}$ & Cases $(\mathbf{n}=\mathbf{5 0 )}$ & \multicolumn{2}{c}{ Controls $(\mathbf{n}=\mathbf{5 0 )}$ p value } \\
\hline$\leq 15$ & 17 & $(34)$ & 50 & $(100)$ & $<0.0001^{* * * *}$ \\
$>15$ & 33 & $(66)$ & & & 0
\end{tabular}

*** Highly significant 


\section{Discussion}

In the present study, the association of serum homocysteine (Hcy) level with PAD in type 2 DM patients was observed. Age, gender and body mass index (BMI) also compared between cases and controls.

In this study, comparison of mean $( \pm S D)$ of age between cases $(62.16 \pm 6.72$ years) and controls $(61.90 \pm 7.14$ years) showed no significant difference $(p>0.05)$. In the present study, no clear-cut family history of PAD was found. Both males and females were included in this study. In cases, there were $28(56 \%)$ males and 22 (44\%) females, and in controls, males were 25 $(50 \%)$ and females were $25(50 \%)$. We observed that males had higher proportion of PAD in comparison to females

Mean $( \pm \mathrm{SD})$ of BMI between cases and controls showed no significant difference $(23.09 \pm 3.57$ vs. $22.45 \pm 3.11, p=0.341)$. In the present study, mean $( \pm S D)$ of serum homocysteine level in the cases and controls were $15.95 \pm 1.80$ and $9.31 \pm 2.11 \mu \mathrm{mol} / \mathrm{L}$ respectively. We found that serum homocysteine level in cases was significantly higher than that of controls $(\mathrm{p}<0.001)$. These results were similarly reported by other workers of different countries ${ }^{12,13,14}$.

In cases, $66 \%$ patients had hyperhomocysteinemia, and in controls homocysteine level was normal in all patients. In this study, raised Hcy level in cases may be associated with the acceleration of pathophysiology of peripheral arterial disease. The possible causes of raised Hcy in cases may be due to genetic, metabolic and dietary causes. Here, dietary causes specially vitamin B6, folate and vitamin $\mathrm{B}_{12}$ deficiency may be a cause of hyperhomocysteinemia, because these vitamins are related to Hcy metabolism.

Increased serum Homocysteine level is associated with PAD in type 2 diabetes mellitus. Males have higher proportion of PAD than females. Early detection is the corner stone for proper management of PAD in type 2 diabetes mellitus, which will reduce morbidity and mortality. For early detection of PAD, comparatively less expensive method is a prerequisite. Ankle brachial index (ABI) measurement is the common tool for diagnosis of peripheral arterial disease. ABI measurement by palpatory method is inexpensive and simple but not highly reliable. ABI measurement by hand held Doppler probe is highly reliable but not available in our country. Diagnosis of PAD by Doppler ultrasound is highly expensive, which is not applicable for a developing country like us. On the other hand, use of serum Hcy measurement as a screening test for peripheral arterial disease warrants further evaluation. So, measurement of ABI by palpatory method and estimation of serum homocysteine in type 2 diabetic patients every year after 40 years of age might be advised. These procedures may be helpful for diagnosis of PAD, specially asymptomatic peripheral arterial disease. Patients with raised serum homocysteine level should be given special care to normalize their serum Hcy level. Other measures including normalization of $\mathrm{BP}$, restriction of smoking, normalization of lipid profile and good control of diabetes should be done to prevent PAD. Supplementation of vitamin $\mathrm{B}_{6}$, folate and vitamin $\mathrm{B}_{12}$ has been shown to reduce circulating levels of homocysteine ${ }^{10}$. Fibric acid derivatives and metformin, drugs that are commonly used in the treatment of patients with diabetes mellitus also increase serum Hcy level ${ }^{15}$. These drugs might be restricted to type 2 diabetic patients with hyperhomocysteinemia. Thiozolidinedione and troglitazone may be advised because these drugs has been claimed to reduce serum homocysteine level

\section{References}

1. Frier BM, Fisher M. Diabetes mellitus. In: Colledge, N.R., Walker, B.R. and Ralston, S.H., eds. 2010. Davidson's Principles and Practice of Medicine. Edinburgh: Churchill Livingstone, 2010:798- 833.

2. Fowkes FGR. Epidemiology of peripheral vascular disease. Atherosclerosis 1997; 131, S 29-31.

3. Walters DP, Gatling W, Mullee MA, Hill RD. The prevalence, detection and epidemiological correlates of peripheral vascular disease: A comparison of diabetic and non-diabetic subjects in an English community. Diabet Med 1992; 9: 710-715. 
H Howlader, S Ahmed, N Sultana et al

4. Dorobantu M, Tirziu C, Ghiorghe H, Gainoiu E, Zamfir D. The prevalence of peripheral arterial disease in relationship with cardiovascular risks factors in Romania. Rom J Intern Med 2009; 47: 363-369.

5. Mohan V, Vijayaprabha R \& Rema M.Vascular complications in long term south Indian NIDDM of over 25 years duration. Diab Res Clinl Pract 1999; 31: 233-140.

6. Kanjwal MK, Cooper C, Bashir R. Peripheral arterial disease - The silent killer. J Practitioner 2004; 11: 225- 232.

7. Fonseca V, Desouza C, Asnani S, Jialal I. Nontraditional risk factors for cardiovascular disease in diabetes. End Rev 2004; 25: 153-175.

8. George N, Welch MD, Loscalzo J. Homocysteine and atherothrombosis. N Eng J Med 1998; 338: 1042-1050.

9. Clarke R, Daly L, Naughten E, Cahalene S, Flower B Garham I 1991.Hyperhomocysteinemia: an independent risk factor for vascular disease. N Eng J Med 1991; 324: 1149-1155.

10. Champe, P.C., Harvey, R.A. and Ferrier, D.R. eds., 2010. Lippincott's Illustrated Reviews: Biochemistry. Bultimore, MD: Lippincott Williams \& Wilkins. p. 265.
11. Afsana F, Latif ZA, Haq MM. Parameters of metabolic syndrome are markers of coronary heart disease - An observational study. Int J Diabet Mell 2010; 2: 83-87

12. Ueland PM, Refsum H, Stabler SP, Malino MR, Andersson A and Allen RH. Total homocysteine in plasma or serum: methods and clinical application. Clin Chem 39; 1993: 1764-1779.

13. Kaswardhani RAT, Suastica K. Age and homocysteine were risk factor for peripheral arterial disease in elderly with type 2 diabetes mellitus. Acta Med Indones J Inern Med 2010; 42: 94- 99.

14. Loncar R, Harboca V, Tavacovic- Loncar V, Ostojic Z, Deussen A. Screening of plasma homocysteine in peripheral arterial disease. Ann Med 2001; 33: 48-54.

15. Desousa C, Keebler M, McNamara DB, Fonseca V. Drugs affecting homocysteine metabolism; Impact on cardiovascular risk. Drugs 2002; 62: 605-616. 